\title{
Irrigação com água salina e uso de substratos na cultura do feijão-caupi
}

\author{
Bruno Eduardo Lopes SOUSA ${ }^{1}$, Geocleber Gomes de SOUSA ${ }^{1}$, Andreza de Melo MENDONÇA², \\ Max Ferreira dos SANTOS ${ }^{2 *}$, Francisco Barroso da SILVA JUNIOR², \\ João Gutemberg Leite MORAES ${ }^{1}$
}

\author{
${ }^{1}$ Universidade da Integração Internacional da Lusofonia Afro-Brasileira, Redenção, CE, Brasil. \\ 2Programa de Pós-graduação em Ciência do Solo, Universidade Federal do Ceará, Fortaleza, CE, Brasil. \\ *E-mail: maxsantos@gmail.com \\ (ORCID: 0000-0003-0674-9349; 0000-0002-1466-6458; 0000-0002-6296-2526; 0000-0002-6597-8865; \\ 0000-0001-9203-3886; 0000-0002-3340-2191)
}

Recebido em 12/02/2020; Aceito em 31/01/2021; Publicado em 11/02/2021.

\begin{abstract}
RESUMO: Objetivou-se avaliar a interação entre diferentes níveis salinos e substratos sob o crescimento inicial, o acúmulo de biomassa e as trocas gasosas da cultura do feijão-caupi. O experimento foi conduzido na área experimental da Universidade Federal do Ceará, Fortaleza, Ceará. O delineamento utilizado foi inteiramente casualizado em esquema fatorial $(5 \times 2)$, com quatro repetições. Os tratamentos foram constituídos por substratos inseridos ao solo (T1- biocarvão + solo na proporção 1:1; T2- solo (testemunha); T3- adubação mineral; T4- casca de arroz carbonizada + carnaúba + solo na proporção 2:1:1 e S5- casca de arroz carbonizada + solo na proporção 1:1), e duas águas de irrigação (1,0 e 4,0 dS m²). Aos 40 dias após a semeadura (DAS) foram avaliados: número de folhas $(\mathrm{NF})$, altura de planta (AP), diâmetro do caule (DC), área foliar (AF), massa seca da parte aérea (MSPA) e total (MST), fotossíntese (A), transpiração (E) e condutância estomática (gs). A água de alta salinidade afetou negativamente a AP, DC, MSPA e a gs das plantas. Os tratamentos T4 e T5 promoveram maior NF e A quando combinado com água não salina. Os tratamentos T4 e T5 proporcionaram maiores valores de gs e E.
\end{abstract}

Palavras-chave: Vigna unguiculata L. Walp; salinidade; adubação.

\section{Influence of saline stress and fertilizers on caupi bean crop}

\begin{abstract}
The objective was to evaluate the effects of salt stress on the initial growth, on the accumulation of biomass and on the gas exchange of the cowpea culture submitted to different substrates. The experiment was conducted in the experimental area of the Federal University of Ceará, Fortaleza, Ceará. The design used was completely randomized in a factorial scheme $(5 \times 2)$, with four replications. The treatments consisted of substrates inserted in the soil (T1- biochar + soil in the proportion 1: 1; T2- soil (control); T3- mineral fertilization; T4- carbonized rice husk + carnauba + soil in the proportion 2: 1: 1 and S5- carbonized rice husk + soil in a 1: 1 ratio), and two irrigation waters (1.0 and $\left.4.0 \mathrm{dS} \mathrm{m}^{-1}\right)$. At 40 days after sowing (DAS), the following were evaluated: number of leaves (NF), plant height (AP), stem diameter (DC), leaf area (AF), shoot dry matter (MSPA) and total (MST), photosynthesis (A), transpiration (E) and stomatal conductance (gs). High salinity water negatively affected AP, DC, MSPA and plant gas. The treatments T4 and T5 promoted greater NF and A when combined with non-saline water. The treatments T4 and T5 provided higher values of gs and E.
\end{abstract}

Keywords: Vigna unguiculata L. Walp; salinity; fertilization.

\section{INTRODUÇÃO}

O feijão-caupi (Vigna unguiculata (L.) Walp.) é uma leguminosa anual de porte herbáceo, autógama, rica em proteína e que tem grande versatilidade na sua utilização e comercialização. No Brasil, essa espécie é de suma importância para as regiões Norte e Nordeste pelo seu alto potencial produtivo e excelente valor nutritivo (FREIRE FILHO et al., 2011).

$\mathrm{Na}$ região Nordeste, a maior demanda por água de irrigação tem levado à utilização da maioria das fontes hídricas disponíveis, dessa forma, os produtores utilizam águas de diferentes níveis de salinidade em algum momento do ciclo das culturas (COSTA et al., 2012). Os sais presentes na água de irrigação retardam o crescimento (PEREIRA FILHO et al., 2017) e alteram os fatores fisiológicos (fotossíntese, transpiração e condutância estomática) da cultura do feijão-caupi (Sousa et al., 2014).

Uma prática conservacionista de caráter edáfico (adubação orgânica ou mineral), vem sendo utilizada para mitigar o estresse salino em algumas culturas agrícolas, como descrevem Prazeres et al. (2015) ao verificaram que adubação mineral com potássio elevou a transpiração e a condutância estomática na cultura do girassol. Já com fontes orgânicas, Souza et al. (2019) estudando biofertilizantes bovino e caprino na cultura da fava irrigada com águas salinas, evidenciaram resposta positivas no crescimento e nas trocas gasosas.

Dessa forma, objetivou-se avaliar a interação entre diferentes níveis salinos e substratos sob o crescimento inicial, o acúmulo de biomassa e as trocas gasosas da cultura do feijão-caupi. 


\section{MATERIAL E MÉTODOS}

O experimento foi conduzido a pleno sol na área experimental da Estação Agrometeorológica da Universidade Federal do Ceará, Fortaleza, Ceará. O clima da região é Aw’, caracterizado por estação quente e chuvosa no verão e moderadamente seca no inverno (KÖPPEN, 1923), apresentando a precipitação anual de $1.564 \mathrm{~mm}$, temperatura média $27,0^{\circ} \mathrm{C}$ e a umidade relativa do ar média de $78 \%$.

Foram utilizados vasos com capacidade de $8 \mathrm{~L}$. O solo utilizado foi classificado como Argissolo Vermelho Amarelo (EMBRAPA, 2018), localizado nas proximidades da área experimental, coletado na profundidade de $0-0,20 \mathrm{~cm}$.
O delineamento experimental utilizado foi o inteiramente casualizado em esquema fatorial (5 x 2), com quatro repetições. Os tratamentos foram constituídos por 5 substratos inseridos no solo (T1- biocarvão + solo na propoção 1:1; T2- solo (testemunha); T3- adubação mineral, (NPK 10:28:20); T4- casca de arroz carbonizada + carnaúba + solo na proporção 2:1:1 e T5- casca de arroz carbonizada + solo na proporção 1:1), e duas água de irrigação: A1- (1,0 $\left.\mathrm{dS} \mathrm{m}^{-1}\right)$, abaixo e $\mathrm{A} 2-\left(4,0 \mathrm{dS} \mathrm{m}^{-1}\right)$ acima da salinidade limiar para a cultura do feijão.

Os atributos químicos do substrato que compõe cada tratamento estão apresentados na Tabela 1.

Tabela 1. Composição química dos tratamentos com os substratos utilizados no estudo.

Table 1. Chemical composition of treatments with the substrates used in the study.

\begin{tabular}{|c|c|c|c|c|c|c|c|c|c|c|c|c|}
\hline \multirow{2}{*}{ Tratamentos } & \multirow{2}{*}{$\begin{array}{c}\mathrm{pH} \\
\text { (água) }\end{array}$} & \multirow{2}{*}{$\begin{array}{c}C E \\
\left(\mathrm{dS} \mathrm{m}^{-1}\right)\end{array}$} & \multirow{2}{*}{$\begin{array}{l}\text { M.O. } \\
\left(\mathrm{g} \mathrm{kg}^{-1}\right)\end{array}$} & \multirow{2}{*}{$\begin{array}{c}\mathrm{P} \\
\left(\mathrm{mg} \mathrm{kg}^{-1}\right)\end{array}$} & $\mathrm{K}$ & $\mathrm{Ca}$ & $\mathrm{Na}$ & $\mathrm{Mg}$ & $(\mathrm{H}+\mathrm{Al})$ & $\mathrm{T}$ & $\mathrm{Al}$ & \multirow{2}{*}{$\begin{array}{c}\mathrm{V} \\
(\%)\end{array}$} \\
\hline & & & & & \multicolumn{7}{|c|}{ 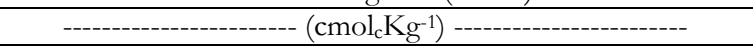 } & \\
\hline $\mathrm{T} 1$ & 7,3 & 0,90 & 20,74 & 5 & 0,70 & 1,80 & 0,41 & 0,50 & 0,17 & 3,60 & 0 & 95 \\
\hline $\mathrm{T} 2$ & 5,8 & 0,32 & 6,00 & 14 & 0,17 & 1,40 & 0,11 & 1,10 & 0,99 & 3,80 & 0,10 & 74 \\
\hline $\mathrm{T} 4$ & 5,6 & 3,11 & 42,90 & 127 & 1,92 & 3,50 & 1,19 & 1,70 & 2,48 & 10,80 & 0,40 & 77 \\
\hline T5 & 6,9 & 0,64 & 16,06 & 37 & 0,97 & 1,80 & 0,27 & 0,50 & 0,99 & 4,50 & 0,05 & 78 \\
\hline
\end{tabular}

T1 (biocarvão + solo); T2 (solo); T3 (adubação mineral); T4 (Casca de arroz carbonizada + carnaúba + solo); T5 (Casca de arroz carbonizada + solo).

A quantidade dos sais $\mathrm{NaCl}, \mathrm{CaCl}_{2} \cdot 2 \mathrm{H}_{2} \mathrm{O}, \mathrm{MgCl}_{2} \cdot 6 \mathrm{H}_{2} \mathrm{O}$, utilizadas no preparo da água de irrigação foi determinada de forma a se obter a CEa desejada na proporção 7:2:1 (RHOADES et al., 2000). A irrigação foi realizada com uma frequência diária, de acordo com o princípio do lisímetro de drenagem (BERNARDO et al., 2019) e mantendo-se o solo na capacidade de campo. O volume aplicado foi estimado em um lisímetro (vaso), por tratamento, pela diferença entre volume aplicado e o volume drenado, seguindo uma fração de lixiviação fixa de $15 \%(0,15)$ de acordo com Ayers e Westcot (1999).

O plantio das sementes de feijão foi realizado semeandose 5 sementes por vaso. Aos 10 dias após a semeadura (DAS) foi realizado desbaste, deixando apenas duas plantas por vaso e as plantas começaram a ser irrigadas a A2 (água com 4,0 dS. $\left.\mathrm{m}^{-1}\right)$.

Aos 40 DAS, avaliaram-se as seguintes variáveis: número de folhas (NF), altura de planta (AP), com trena métrica graduada em centímetro, diâmetro do caule (DC), medido utilizando um paquímetro digital em $\mathrm{mm}$, área foliar (método do Scanner - utilizou-se um digitalizador de imagens (Scanner), acoplado a um microcomputador, onde a imagem foi analisada pelo software Sigmascan ${ }^{\circledR}$ para a realização do cálculo da área) comprimento da raiz (CR). Em seguida, as plantas foram coletadas e separadas em folhas e raiz e colocadas em sacos de papel para secar em estufa de circulação forçada de ar a $60^{\circ} \mathrm{C}$ para determinação da matéria seca da parte aérea e da raiz. Nesse mesmo período, foram analisadas as seguintes variáveis: fotossíntese (A), transpiração (E) e condutância estomática (gs), utilizando-se um analisador de gás no infravermelho IRGA (LI 6400 XT da LICOR), em sistema aberto, com fluxo de ar de $300 \mathrm{~mL}$ $\mathrm{min}^{-1}$; as medições foram feitas entre 10 e $12 \mathrm{~h}$, em folhas completamente expandidas.

Os resultados obtidos foram submetidos à análise de variância pelo teste $\mathrm{F}$ ao nível de 1 e $5 \%$ de probabilidade e as médias foram comparadas ao teste de Tukey, utilizando-se o programa Assistat 7.7 beta.

\section{RESULTADOS}

De acordo com os dados apresentados na Tabela 2, houve interação significativa a entre substratos e condutividade elétrica da água apenas para o número de folhas e a fotossíntese, a um nível de ( $\mathrm{p}<0,01$ e $\mathrm{p}<0,05)$. Já as variáveis altura de planta e diâmetro de caule, responderam de forma isolada a salinidade da água. Para a matéria seca da parte aérea e total observou-se efeitos deletérios quando se utilizou água alta salinidade. Observa-se que os diferentes fertilizantes afetaram a transpiração das plantas. Já a condutância estomática o diâmetro do caule e a altura de plantas, foram influenciados pelas formas de adubação e salinidade da água. No entanto, os diferentes fatores não afetaram negativamente as variáveis: área foliar, comprimento de raiz e massa seca da raiz.

Na Figura 1 é possível observar que a menor média para as variáveis altura de planta (AP) e diâmetro do caule (DC) foram obtidas no substrato T2 (solo), diferindo estatisticamente dos demais. Esses resultados podem estar relacionados ao menor aporte de nutrientes nesse tratamento. Vale destacar que a maior quantidade de nitrogênio na concentração desses substratos, acarreta maior crescimento das plantas (PRADO, 2008).

Para a transpiração (Figura 1C), houve efeito isolado para o fator substratos, revelando diferença estatística dos tratamentos T4 e T5 quando comparados aos outros substratos. Esse resultado pode estar associado ao efeito de cobertura morta dos substratos orgânicos, isto é, diminuindo a evaporação do solo e proporcionando maior manutenção do potencial hídrico foliar por mais tempo devido à ação de cobertura e melhoria de porosidade dos substratos.

De acordo com a Figura 1D, assim como para a transpiração, os tratamentos T4 e T5 também evidenciaram maior condutância estomática. Os substratos adicionados ao solo, excetuando T3, promoveram valores superiores quando comparados ao tratamento testemunha, isso pode estar relacionado a uma melhoria no suprimento nutricional para a planta, de modo que, o suprimento inadequado de elementos às plantas causa distúrbios fisiológicos (TAIZ et al., 2017).

Conforme a Figura 2A e 2B a alta concentração de sais contida na água de irrigação afetou negativamente a altura de plantas e diâmetro de caule. É possível que o estresse salino tenha atrasado o crescimento da planta por influenciar na redução da água disponível no solo, promovendo maior necessidade da planta em gastar energia para absorver água e 
se desenvolver (SOUZA et al., 2019).

Tabela 2. Resumo da análise de variância (ANOVA) para altura de planta (AP), número de folhas (NF), área folear (AF), comprimento de raiz (CR), diâmetro do caule (DC), massa seca da parte aérea (MSPA), massa seca da raiz (MSR), massa seca total (MST), fotossíntese (A), transpiração (E) e condutância estomática (gs) de plantas de feijão-caupi em função de diferentes substratos e salinidade da água de irrigação. Table 2. Summary of analysis of variance (ANOVA) for plant height (AP), number of leaves (NF), leaf area (AF), root length (CR), stem diameter (DC), dry mass of the part (MSPA), root dry matter (MSR), total dry mass (MST), photosynthesis (A), transpiration (E) and stomatal conductance (gs) of cowpea plants as a function of different substrates and water salinity irrigation.

\begin{tabular}{|c|c|c|c|c|c|c|c|c|c|c|c|c|}
\hline$\overline{\mathrm{FV}}$ & & & & & & Quadra & o Médio & & & & & \\
\hline & & $\mathrm{AP}$ & $\mathrm{NF}$ & $\mathrm{AF}$ & CR & DC & MSPA & MSR & MST & A & $\mathrm{E}$ & gs \\
\hline Tratamentos & 9 & $6,22 *$ & $10,22^{* *}$ & $264,80^{\mathrm{ns}}$ & $11,16^{\mathrm{ns}}$ & $0,89 *$ & $2,15^{* *}$ & $0,41 *$ & $3,24^{* *}$ & $15,50 * *$ & $1,36^{* *}$ & $0,021 * *$ \\
\hline Água (AG) & 1 & $14,40^{*}$ & $55,22^{* *}$ & $253,76^{\mathrm{ns}}$ & $4,00^{\mathrm{ns}}$ & $2,17^{*}$ & $11,52^{* *}$ & $0,58^{\text {ns }}$ & $17,30 * *$ & $2,96^{\mathrm{ns}}$ & $0,64^{\mathrm{ns}}$ & $0,030^{* *}$ \\
\hline Substratos (SB) & 4 & $7,29 *$ & $4,66^{*}$ & 294,93 ns & $19,84^{\mathrm{ns}}$ & $1,31 * *$ & $0,60^{\text {ns }}$ & $0,48^{\mathrm{ns}}$ & $1,16^{\mathrm{ns}}$ & $25,29 * *$ & $2,62^{* *}$ & $0,034 * *$ \\
\hline$A G \times S B$ & 4 & $3,10^{\text {ns }}$ & $4,53 *$ & $237,43^{\text {ns }}$ & $4,24^{\mathrm{ns}}$ & $0,47 \mathrm{~ns}$ & $1,36^{\text {ns }}$ & $0,30^{\mathrm{ns}}$ & $1,79 \mathrm{~ns}$ & $8,84^{*}$ & $0,27^{\mathrm{ns}}$ & $0,006^{\mathrm{ns}}$ \\
\hline Resíduo & 30 & 2,33 & 697,63 & 177,53 & 6,97 & 0,31 & 0,55 & 0,17 & 0,82 & 264,68 & 0,19 & 0,003 \\
\hline Total & 39 & & & & & & & & & & & \\
\hline$\overline{\mathrm{MG}}$ & & 9,75 & 4,32 & 47,33 & 10,85 & 4,59 & 196,75 & 0,60 & 256,82 & 747,95 & 215,70 & 0,14 \\
\hline CV $(\%)$ & & 15,67 & 25,59 & 28,15 & 24,36 & 12,32 & 37,88 & 0,60 & 35,44 & 21,75 & 20,39 & 41,61 \\
\hline
\end{tabular}

FV: Fonte de variação, GL: Grau de liberdade, CV (\%): Coeficiente de variação, $\mathrm{MG}=$ média geral, $*$ Significativo pelo teste $\mathrm{F}$ a $5 \%$; ** Significativo pelo teste F a $1 \%$; ns = não significativo.
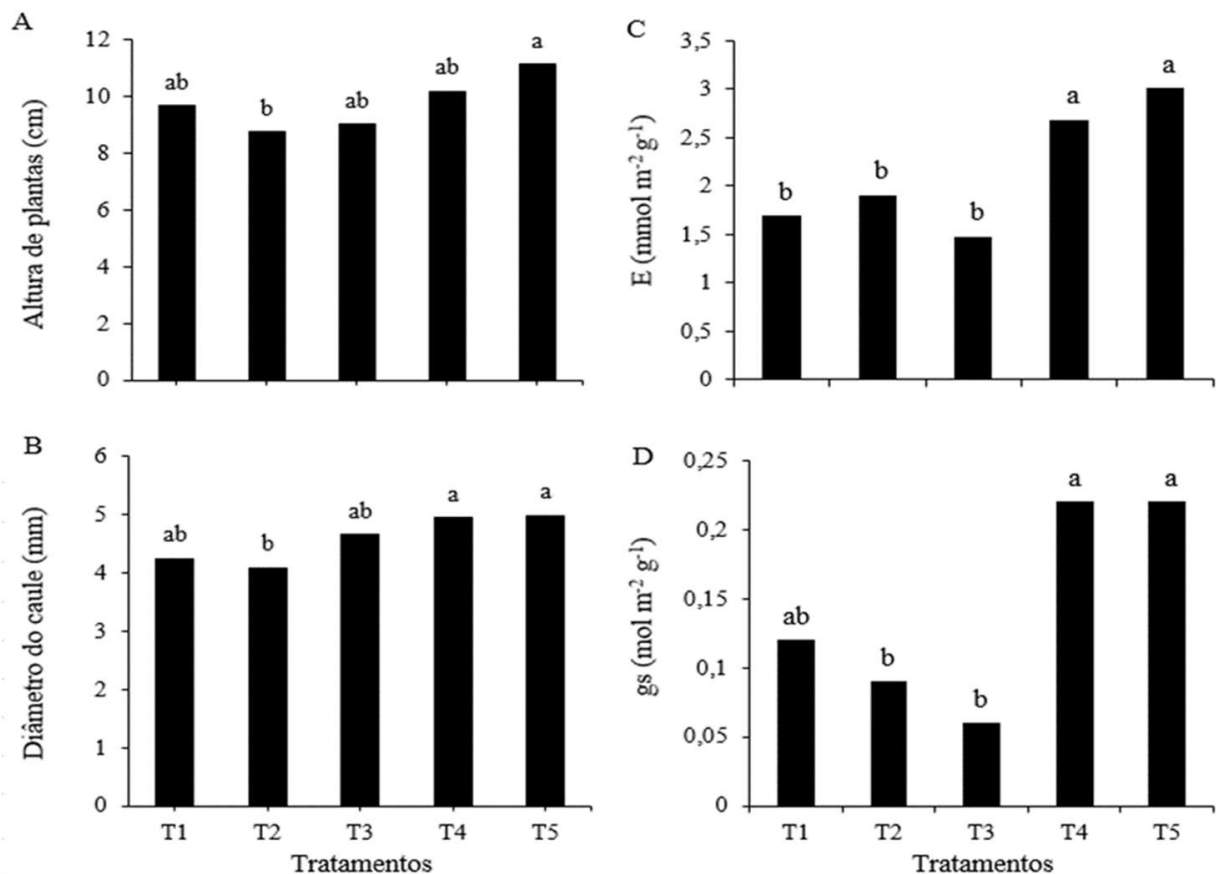

Figura 1. Altura de planta (A), diâmetro do caule (B), transpiração (C) e condutância estomática (D) do feijão-caupi em função em diferentes tipos de substratos.

Figure 1. Plant height (A), stem diameter (B), transpiration (C) and stomatal conductance (D) of cowpea depending on different types of substrates.

Observa-se na Figura 2C e 2D a água de alta salinidade afetou negativamente a massa seca da parte aérea e seca total (MST). Essa redução está relacionada a realocação de energia devido ao aumento de níveis de salinidade, dessa forma, essa redução é reflexo da diminuição de energia metabólica nas plantas. (SOUSA et al., 2018).

De acordo com a Tabela 3, a água de condutividade elétrica elevada reduziu significativamente o número de folhas, em compensação a água de baixa salinidade, excluindo T2, foi superior estatisticamente aos demais tratamentos. Os resultados evidenciam a influência dos nutrientes presentes nos fertilizantes. Ou seja, possivelmente os nutrientes essenciais como o nitrogênio e o potássio promoveram maior crescimento em número de folhas (PRADO, 2008).

Verifica-se ainda na tabela 3, que o estresse salino e os substratos afetaram negativamente os tratamentos T2 e T3 para fotossíntese. Já a água de baixa salinidade promoveu melhores resultados para taxa fotossintética em todos os substratos, exceto o T2.

Embora a fotossíntese tenha sido estimulada na presença dos substratos, quando irrigada com água de baixa salinidade, o estresse salino reduziu a taxa fotossintética. Ou seja, os sais acumulados nos cloroplastos das células, afetam diretamente a fotossíntese das plantas (TAIZ et al., 2017), causando fechamento estomático parcial, e consequentemente também uma redução na disponibilidade de $\mathrm{CO}_{2}$ para folhas (PEREIRA FILHO et al., 2019).

Ressalta-se que o estresse salino afeta na redução de condutância estomática, promovendo declínio na fotossíntese líquida, devido à uma menor pressão parcial do $\mathrm{CO}_{2}$ nos espaços intercelulares (PEREIRA FILHO et al., 2019). O estresse salino promovido pelo aumento da concentração de sais na água de irrigação reduziu significativamente a condutância estomática das plantas (Figura 4). 

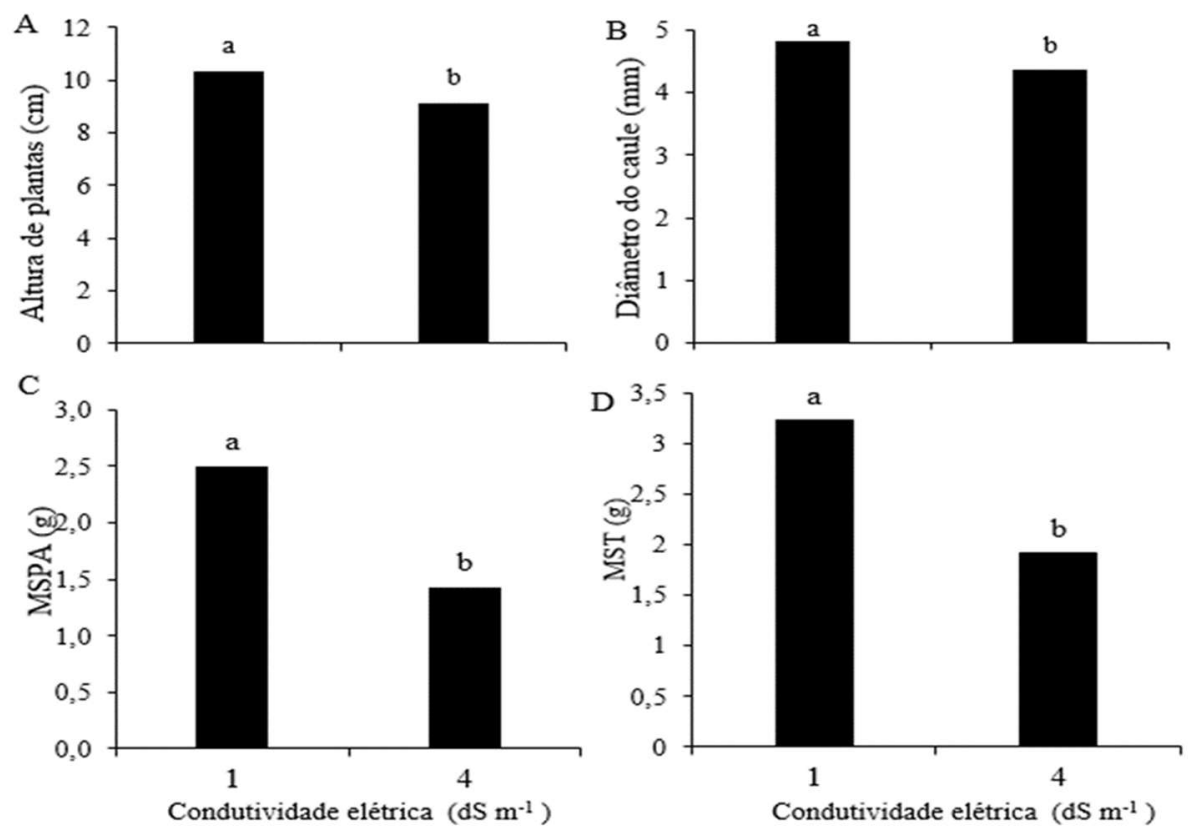

Figura 2. Altura de planta (A), diâmetro do caule (B), massa seca da parte aérea (C) e massa seca total (D) do feijão-caupi irrigada com águas de diferentes condutividades elétricas (CEa).

Figure 2. Plant height (A), stem diameter (B), shoot dry mass (C) and total dry mass (D) of cowpea irrigated with water of different electrical conductivities $(\mathrm{CEa})$.

Tabela 3. Valores médios de número de folhas e fotossíntese da cultura do feijão adubada com diferentes substratos e irrigada com água de baixa e alta salinidade.

Table 3. Average values of number of leaves and photosynthesis of bean culture fertilized with different substrates and irrigated with low and high salinity water.

\begin{tabular}{|c|c|c|}
\hline \multirow{3}{*}{ Tratamentos } & \multicolumn{2}{|c|}{ Água de irrigação } \\
\hline & $1,0\left(\mathrm{dS} \mathrm{m}^{-1}\right)$ & $4,0\left(\mathrm{dS} \mathrm{m}^{-1}\right)$ \\
\hline & \multicolumn{2}{|c|}{ Número de folhas } \\
\hline T1 & $4,50 \mathrm{bA}$ & $2,25 \mathrm{bB}$ \\
\hline $\mathrm{T} 2$ & $4,75 \mathrm{abA}$ & $3,00 \mathrm{abB}$ \\
\hline T3 & $4,75 \mathrm{abA}$ & $2,50 \mathrm{abB}$ \\
\hline $\mathrm{T} 4$ & 6,5 abA & $3,25 \mathrm{abB}$ \\
\hline \multirow[t]{2}{*}{ T5 } & $7,00 \mathrm{aA}$ & $4,75 \mathrm{aA}$ \\
\hline & \multicolumn{2}{|c|}{ Fotossíntese } \\
\hline T1 & $6,85 \mathrm{bA}$ & $5,24 \mathrm{aA}$ \\
\hline $\mathrm{T} 2$ & $4,89 \mathrm{bB}$ & $8,08 \mathrm{bA}$ \\
\hline T3 & $5,55 \mathrm{bA}$ & $5,45 \mathrm{aA}$ \\
\hline T4 & $11,68 \mathrm{aA}$ & $8,36 \mathrm{aB}$ \\
\hline T5 & $9,99 \mathrm{abA}$ & $8,68 \mathrm{aA}$ \\
\hline
\end{tabular}

Médias seguidas pela mesma letra maiúscula na linha e minúsculas nas colunas, não diferem entre si pelo teste de Tukey a $5 \%$ de probabilidade.

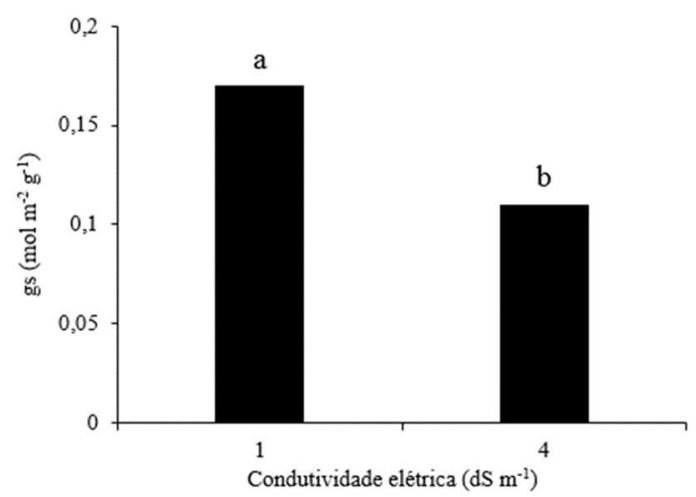

Figura 4. Valores de condutância estomática em plantas de feijãocaupi irrigada com águas de diferentes condutividades elétricas (CEa).

Figure 4. Values of stomatal conductance in cowpea plants irrigated with water of different electrical conductivities $(\mathrm{CEa})$.
Ressalta-se que o estresse salino afeta na redução de condutância estomática, promovendo declínio na fotossíntese líquida, devido à uma menor pressão parcial do $\mathrm{CO}_{2}$ nos espaços intercelulares (PEREIRA FILHO et al., 2019).

\section{DISCUSSÃO}

Adubando com biofertilizante bovino como fonte orgânica a cultura do feijão-caupi, Sousa et al. (2013) constataram resultados semelhantes quanto à altura de plantas. Já Sá et al. (2018) utilizando adubação fosfatada como fonte mineral na cultura do feijão, evidenciaram similaridade aos dados encontrados nesse estudo. Quanto ao diâmetro do caule, Sousa et al. (2013) também detectaram similaridade na cultura do feijão-caupi e Souza et al. (2019) na cultura da fava, ao adubarem com biofertilizante bovino e caprino, respectivamente. Da mesma forma, Sá et al. (2018) também verificaram maior altura de plantas ao efetuarem a adubação fosfatada como fonte mineral na cultura do feijãocaupi.

Para a transpiração, resultados similares foram constatados por Sousa et al. (2013) utilizando adubação fosfatada na cultura do pinhão-manso e por Sousa et al. (2011), aplicando biofertilizante bovino como fertilizante orgânico via solo na cultura do feijão-de-corda, no qual também verificaram efeito positivo para transpiração dessas plantas. Similarmente, Souza et al. (2019) também constataram efeito positivo do biofertilizante caprino para a cultura fava.

Estudos que reportam tendências similares ao desse estudo para a variável condutância estomática, foram reportadas por Sousa et al. (2011), cultivando feijão-de-corda em vaso adubado com biofertilizante bovino e por Viana et al. (2013) ao utilizar biofertilizante misto na cultura do melão.

Em relação às vaiáveis do feijão-caupi quando irrigada com águas de diferentes condutividades elétricas (CEa), os resultados de altura de planta estão em conformidade com 
Sousa et al. (2014), ao detectarem redução na cultura do feijão-caupi irrigada com concentrações elevadas de sais. Similarmente, Pereira filho et al. (2017) também verificaram efeito negativo do estresse salino na altura de plantas de feijão-caupi.

Já para o diâmetro do caule, Pereira Filho et al. (2017) constataram similaridade ao irrigar a cultura do feijão-caupi com águas salinas. De forma semelhante, Sousa et al. (2018) trabalhando com a cultura da soja irrigada com água salina, também verificaram redução do diâmetro do caule.

Para a MSPA, resultados semelhantes foram reportados por Sousa et. al. (2014) e Pereira Filho et al. (2017) na cultura do feijão-caupi, no qual afirmam que o estresse salino decorrente da irrigação com água salina reduz expressivamente a biomassa das plantas.

Para a MST, Souza et al. (2019), também observaram tendência similar na cultura da fava. Esses mesmos autores constataram que o estresse reduziu a biomassa total.

Quanto ao efeito da interação entre a água de irrigação e os diferentes substratos para o número de folhas, Sousa et al. (2014) observaram redução do número de folhas com o aumento da concentração de sais na água de irrigação. No entanto, Kratz et al. (2013) descrevem que a casca de arroz carbonizada pode ser incorporada ao solo por melhorar suas características físicas e químicas e teor adequado de $\mathrm{N}, \mathrm{K}$ e $\mathrm{Ca}$, essenciais para o desenvolvimento vegetal.

Já para a variável fotossíntese, Sousa et al. (2016) observaram similaridade ao estudarem a cultura da laranja utilizando água salobra e adubação nitrogenada como fonte mineral. Já Sousa et al. (2014) verificaram tendência similar para a fotossíntese na cultura do feijão-caupi irrigada com águas salinas e cultivada em solo com fertilizantes orgânicos.

Já a condutância estomática, houve efeito negativo do estresse salino em plantas de feijão-caupi, corroborando com os dados descrito por Sousa et al. (2014) e por Prazeres et al. (2015).

\section{CONCLUSÕES}

A água de alta salinidade afetou negativamente a altura de planta, diâmetro do caule, massa seca da parte aérea, seca total e a condutância estomática de plantas de feijão.

Os tratamentos contendo casca de arroz carbonizada de + carnaúba + solo e casca de carbonizada + solo, promoveu maior número de folhas e fotossíntese quando combinado com água não salina.

Os tratamentos casca de arroz carbonizada + carnaúba + solo e casca de carbonizada + solo, proporcionou maiores valores de condutância estomática e a transpiração.

\section{REFERÊNCIAS}

AYRES, R. S.; WESTCOT, D. W. A qualidade da água na agricultura. 2 ed. Campina Grande: UFPB, 1999. 153p.

BERNARDO, S.; MANTOVANI, E. C.; SILVA, D. D.; SOARES, A. A. Manual de irrigação. 9 ed. Viçosa: Editora UFV, 2019. 545p.

CAVALCANTI, N. B. Influência de diferentes substratos na emergência e crescimento de plantas de feijão de porco (Canavalia ensiformes L.). Engenharia Ambiental, Espírito Santo do Pinhal, v. 8, n. 3, p. 51-70, 2011.

COSTA, F. G. B.; FERNANDES, M. B.; BARRETO, H. B. F.; OLIVEIRA, A. F. M.; SANTOS, W. O. Crescimento da melancia e monitoramento da salinidade do solo com TDR sob irrigação com águas de diferentes salinidades.
Irriga, Botucatu, v. 17, n. 3, p. 327-336, 2012. DOI: https://doi.org/10.15809/irriga.2012v17n3p327

EMBRAPA. Sistema brasileiro de classificação de solos. 5 ed. Brasília, DF: Embrapa, 2018. 356p.

FREIRE FILHO, F. R. Feijão-caupi no Brasil: produção, melhoramento genético, avanços e desafios. Embrapa Meio-Norte, Teresina, 2011. 84p.

KRATZ, D.; WENDLING, I.; NOGUEIRA, A. C.; SOUZA, P. V. D. D. Propriedades físicas e químicas de substratos renováveis. Revista Árvore, Viçosa, v. 37, n. 6, p. 1103-1113, 2013. DOI: http://dx.doi.org/10.1590/S0100-67622013000600012

KÖPPEN, W. P. Die klimate der erde: Grundriss der klimakunde. Berlin: Walter de Gruyter \& So., 1923. $369 \mathrm{p}$.

LACERDA, C. F.; SOUSA, G. G.; SILVA, F. L. B.; GUIMARÃES, F. V. A.; SILVA, G. L.; CAVALCANTE, L. F. Soil salinization and maize and cowpea yield in the crop rotation system using saline waters. Engenharia Agrícola, Jaboticabal, v. 31, n. 4, p. 663-675, 2011. DOI: http://dx.doi.org/10.1590/S0100-69162011000400005

PEREIRA FILHO, J. V.; BEZERRA, F. M. L.; SILVA, T. C.; PEREIRA, C. C. M. S. Crescimento vegetativo do feijão-caupi cultivado sob salinidade e déficit hídrico. Revista Brasileira de Agricultura Irrigada, Fortaleza, v. 11, n. 8, p. 2217-2228, 2017. DOI: http://dx.doi.org/10.7127/RBAI.V11N800718

PRADO, R. M. Nutrição de plantas. 1 ed. São Paulo: Editora Unesp, 2008. 407p.

PRAZERES, S. S.; LACERDA, C. F. de; BARBOSA, F. E. L.; AMORIM, A. V.; ARAÚJO, I. C. DA S.; CAVALCANTE, L. F. Crescimento e trocas gasosas de plantas de feijão-caupi sob irrigação salina e doses de potássio. Revista Agro@mbiente On-line, Boa Vista, v. 9 , n. 2, p. 111-118, 2015. DOI: http://dx.doi.org/10.18227/1982-8470ragro.v9i2.2161

RHOADES, J. D.; KANDIAH, A.; MASHALI, A. M. Uso de águas salinas para produção agrícola. Campina Grande: UFPB, 2000. 117p. (Estudos FAO - Irrigação e Drenagem, 48).

SAIDELLES, F. L. F.; CALDEIRA, M. V. W.; SCHIRMER, W. N.; SPERANDIO, H. V. Casca de arroz carbonizada como substrato para produção de mudas de tamboril-damata e garapeira. Semina: Ciências Agrárias, Londrina, v. 30, suplemento 1, p. 1173-1186, 2009.

SOUSA, G. G.; RODRIGUES, V. S.; SOARES S. C.; DAMASCENO, I. N.; FIUSA J. N.; SARAIVA, S. E. Irrigação com água salina em soja (Glycine max (L.) Merr.) Em solo com biofertilizante bovino. Revista Brasileira de engenharia agrícola e ambiental, Campina Grande, v. 22, n. 9, p. 604-609, 2018. DOI: http://dx.doi.org/10.1590/1807-

1929/agriambi.v22n9p604-609

SOUSA, G. G.; VIANA, T. V. A.; BRAGA, E. S.; AZEVEDO, B. M.; MARINHO, A. B.; BORGES, F. R. M. Fertirrigação com biofertilizante bovino: efeitos no crescimento, trocas gasosas e na produtividade do pinhão-manso. Revista Brasileira de Ciências Agrárias, Recife, v. 8, n. 3, p. 503-509, 2013. DOI: https://doi.org/10.5039/agraria.v8i3a2288

SOUSA, J. R. M.; GHEYI, H. R.; BRITO, M. E. B.; XAVIER, D. A.; FURTADO, G. F. Trocas gasosas e produção de citros irrigados com águas salinas e adubação nitrogenada. Revista Caatinga, Mossoró, v. 
29, n. 2, p. 415-424, 2016.

SOUZA, M. V. P.; SOUSA, G. G.; SALES, J. R. S.; FREIRE, M. H. C.; SILVA, G. L.; VIANA, T. V. A. Saline water and biofertilizer from bovine and goat manure in the Lima bean crop. Revista Brasileira de Ciências Agrárias, Recife, v. 14, n. 3, e5672, 2019. DOI: https://doi.org/10.5039/agraria.v14i3a5672

TAIZ, L.; ZEIGER, E.; MOLLER, I. M.; MURPHY, A. Fisiologia e desenvolvimento vegetal. 5.ed. Porto Alegre: Artmed, 2017. 819p.

VIANA, T. V. A.; SANTOS, A. P. G.; SOUSA, G. G.; PINHEIRO NETO, L. G.; AZEVEDO, B. M.; AQUINO, B. F. Trocas gasosas e teores foliares de NPK em meloeiro adubado com biofertilizantes. Revista Brasileira de Ciências Agrárias, Recife, v. 8, n. 4, p. 595-601, 2013.2 DOI: https://doi.org/10.5039/agraria.v8i4a3260

VIANA, T.V. de A.; LACERDA, C. F.; AZEVEDO, B. M.; SILVA, G. L.; COSTA, F. R. B. Estresse salino em plantas de feijão-caupi em solo com fertilizantes orgânicos. Revista Agro@mbiente, Boa Vista, v. 8, n. 3, p. 359-367, $2014 . \quad$ DOI: http://dx.doi.org/10.18227/1982-8470ragro.v8i3.1824 